\title{
Experimental study of natural convection in the melting of PCM in horizontal cylindrical annuli
}

\author{
Roman Domañski, Tomasz Wiśniewski, Marek Rebow
}

Warsaw University of Technology, Institute of Heat Engineering, Nowowiejska 25, 00-665 Warsaw, Poland

\begin{abstract}
Heat transfer characteristics, including the convective flow driven by melting of subcooled phase change material (PCM) in the horizontal annulus gap, were experimentally studied The inner cylinder was heated with a constant surface heat flux and the outer cylinder had a constant temperature. The history of the temperature field was measured with an infrared scanning system. It is shown in this paper that contribution of natural convection in the melt region becomes significant as the Stefan number increases.
\end{abstract}

\section{Introduction}

In recent years numerous experimental and numerical studies or analytical solutions, have been performed to explain the principal mechanism of energy transfer occurring during the melting or solidification. In many of these practical cases natural convection effects, in the melted region, dominate over diffusion. Also an experimental and numerical investigation has been conducted at the Institute of Heat Engineering to study the characteristics of natural convection for the melting of $n$-octadecan inside a horizontal annulus gap [1-4]. Understanding and predicting the melt behavior of phase change material (PCM) is of special importance in designing cost-effective heat receivers of latent thermal energy storage (LTES).

The temperature field and the solid-liquid interface boundary can be conventionally studied with the help of thermocouples. Another technique used in measurements of such kind is the application of thermochromic liquid crystals (TLC) suspended as small tracer particles. The Particle Image Thermometry (PIT) is based on temperature-dependent reflectivity of TLC at visible light wavelengths [5]. Another sensor to study the solid-liquid interface is optical fiber [6]. This paper reports experimental results on the melting in a horizontal annulus gap using infrared (IR) thermography.

This method has several advantages over measurements performed with usage of thermocouples, especially in experiments on natural convective melting/solidification heat transfer. Some advantages of IR thermography are: it is a non-intrusive measurement of temperature in the whole test cell (not only in the chosen points), it leads to simultaneous measurements of temperature and progress of the liquid-solid interface, it avoids disturbance of the heat flow caused by the presence of the numerous thermocouples.

\section{Experimental apparatus and procedure}

The experimental set-up is shown in figure. 1 . The test annular cavity (3) is bounded by two co-axial, horizontal cylinders with diameters $30 \mathrm{~mm}$ and $90 \mathrm{~mm}, 70 \mathrm{~mm}$ long. The main heat source is the electrical heater (1) inserted in the inner cylinder (2). Electrical power is controlled by a wattmeter. The initial conditions are maintained by water flowing through a heat exchanger coil (7) which is soldered on the outer cylinder (6). The temperature of the water is controlled by a thermostat. To allow measurements and visualization of the phase change inside the annulus gap, the front of the rectangular box was made of acrylic plate of $5 \mathrm{~mm}$ thickness (9). An overflow tube (13) is used for expansion or contraction of the PCM upon change of phase. The outer-side of the window is covered by $50 \mathrm{~mm}$ thick foam insulation (10) 
to obtain an adiabatic boundary condition. This insulation is removed for a couple of seconds during IR measurements.

As PCM $99,9 \%$ pure $n$-octadecan $\left[\mathrm{CH}_{3}\left(\mathrm{CH}_{2}\right)_{16} \mathrm{CH}_{3}\right]$ was used. This material was selected because: (1) its melting point is $28^{\circ} \mathrm{C}$ and enables reduction of heat losses to the ambient environment, (2) its physical properties are well known. To prevent formation of bubbles during melting, the PCM was degassed before the experiments by vacuum. The temperature of the PCM was set at $23^{\circ} \mathrm{C}\left(5^{\circ} \mathrm{C}\right.$ of subcooling) with $0.2^{\circ} \mathrm{C}$ homogeneity, before the melting experiment was started. After reaching solid temperature equilibrium, the melting of PCM around the inner cylinder was begun by step increase in electrical power supplied to the internal heater. The experiments were conducted for surface heat fluxes equal to $q_{w}=\mathbf{2 . 2}$ and $q_{w}=1.0 \mathrm{~kW} / \mathrm{m}^{2}$ and Stefan numbers equal to 4 and 1.8 respectively.

The distributions of temperature on the outer-side surface of the acrylic window at prescribed intervals were measured by the Thermovision 900 SW/TE System produced by AGEMA Infrared Systems $A B$. This system operates in the 2-5,4 $\mu \mathrm{m}$ infrared waveband with sensitivity of $0.1^{\circ} \mathrm{C}$ at $30^{\circ} \mathrm{C}$, accuracy of $\pm 1^{\circ} \mathrm{C}$ (range 1) and repeatability of $\pm 0,5^{\circ} \mathrm{C}[7]$.

Reference thermocouples (4) placed at the inner and outer surface of the window, and inside the PCM gap, are used to correct temperature readings of the IR system, to estimate heat losses through the window and to determine the temperature difference between liquid PCM and the window surface. Analysis of IR thermograms with AGEMA software ERIKA 3.11 allowed to obtain many data describing the investigated phenomena. In particular, it was possible to obtain the required isotherms, to determine the position of the melting front and to measure the liquid region area necessary to calculate the melting volume fraction. An example of experimental results analyzed with ERIKA 3.11. software is presented in figure 2.

\section{Results and discussion}

The temperature measurements performed with thermocouples proved that the natural convection between the outer surface of the window and ambient air during IR measurements is very small and can practically be neglected. Therefore, after setting the correct emissivity of the surface (with thermocouples), the temperature field of the outer surface of the window, determined with the IR camera is practically coincident with the temperature field in the solid region of the PCM. However, due to natural convection in the melted volume of the PCM some temperature gradients $\left(1 \div 1.5^{\circ} \mathrm{C}\right)$ between the liquid and window surface occur. Therefore, the results obtained with IR thermogarphy in the melted region should be verified, for example, by performing temperature measurements with thermocouples at some characteristic points.

The presentation of the results consists of the progress of the melting front shape and time variation of the melt volume. The sequence of thermographic images shown in figure. 3 identifies the melting stages. During the initial stage, heat was transferred to the subcooled solid region only by conduction and no melting occurred until the surface temperature of the heater reached the melting point $\left(28^{\circ} \mathrm{C}\right)$. In the second stage, natural convection occurred in the upper part of the melted region. During the quasi-steady melting, the melting front was keyhole-shaped. Below the heated cylinder, no significant melting was observed.

Figure 4 shows the position of the solid-liquid interface and ist progress as a function of Fourier number Fo for three angular positions $\theta=0^{\circ}, 90^{\circ}$ and $180^{\circ}$, where $\theta$ is measured from the downward vertical line. At $\theta=180^{\circ}$ and $F o=0.338$ the interface position for Ste $=4$ is about 3 times greater than for Ste $=1.8$. It appears that the increase of input heat flux increases the contribution of natural convection, which enhances the movement of the upper portion of the melted region.

The dimensionless melt volume $\left(V_{m} N_{a}\right)$ dependence with time for the different Ste numbers is plotted in figure 5. The melt volume increases linearly with time, because the heat transfer is 
approximately constant during the quasi-steady melting. The melted fraction volume for Ste = 4 is about 3 times higher than that for Ste $=1.8$.

\section{Concluding remarks}

The following conclusions can be drawn from the present experimental studies:

- the Stefan number effect on melting of subcooled PCM in a horizontal cylindrical annuli was examined quantitatively by experimental analysis; it was shown that the contribution of natural convection becomes significant as the Stefan number increases,

- use of IR thermography in such kind of experiments allows to obtain the whole temperature field in the test region without disturbing the heat flow; only few thermocouples are used to make corrections of temperature readings from the IR system and controlling heat losses,

- the use of experimental data obtained by means of IR measurement enables better validation of numerical results and improvement of numerical calculation,

- further experimental investigations with the use of IR thermography will allow to collect more details on the different flow structures in the melting of PCM caused by imposed initial and boundary conditions.

\section{Acknowledgments}

This work was supported by State Committee for Scientific Research Grant No. PB 698/T10/96/111

\section{NOMENCLATURE}

\begin{tabular}{|c|c|}
\hline$a_{4}$ & liquid thermal diffusivity, $\mathrm{m}^{2} / \mathrm{s}$ \\
\hline$c_{i}$ & liquid specific heat, $\mathrm{J} /(\mathrm{kg} \cdot \mathrm{K})$ \\
\hline Fo & Fourier number $\left(=a_{1} t\left(r_{0}-r_{i}\right)^{2}\right)$, dimensionless \\
\hline$k_{1}$ & liquid thermal conductivity, $\mathrm{W} /(\mathrm{m} \cdot \mathrm{K})$ \\
\hline L & latent heat, J/kg \\
\hline$q_{w}$ & surface heat flux at the inner cylinder, $\mathrm{W} / \mathrm{m}^{2}$ \\
\hline$r_{i}$ & inner cylinder radius, $\mathrm{m}$ \\
\hline$r_{0}$ & outer cylinder radius, $m$ \\
\hline $\begin{array}{l}\text { Ste } \\
t\end{array}$ & $\begin{array}{l}\text { Stefan number }\left(=c_{1} q_{w}\left(r_{0}-r_{i}\right) / k_{1} L\right) \text {, dimensionless } \\
\text { time, } s\end{array}$ \\
\hline
\end{tabular}

\section{REFERENCES}

[1] EL-SAYED (A.O.), DOMAÑSKI (R.), JAWORSKI (M.). - An experimental study for the melting of PCM inside concentric horizontal cylindrical annuli. Proc. of 6 th International Conference on Thermal Energy Storage CALORSTOCK '94. Espoo, Finland 1994. pp. 503512.

[2] DOMAÑSKI (R.), OWES (A.), JAWORSKI (M.). - Melting Characteristic of PCM Inside the Annulus Gap. Zeszyty Naukowe Polit. CEwiêtokrzyskiej, Mechanika 53, Kielce 1994.

[3] EL-SAYED (A.O.). - Experimental and numerical investigation of the melting phenomenon of encapsulated PCM in horizontal cylindrical annuli. Ph.D. Thesis, Warsaw University of Technology, Warsaw 1995. 
[4] DOMAŃSKI (R.), EL-SAYED (A.O.), JAWORSKI (M.), REBOW (M.). - A Comparison of Calculated and Experimental Results for the Melting of PCM in Horizontal Cylindrical Annuli. IX Sympozjum Wymiany Ciepła i Masy - Augustów 1995.

[5] HILLER (W.J.), KOCH (St.), KOWALEWSKI (T.A.), STELLA (F.). - Onset of natural convection in a cube. Int. J. Heat Mass Transfer, Vol. 36, 1993, p. 3251-3263.

[6] BUDDHI (D.), MURTHY (V.V.). - Comparison of using thermocouple and optical fibre to study the solid-liquid boundary in phase change materials. Energy Convers. Mgmt., Vol. 37, No 5, 1996, p. 637-639.

[7] AGEMA Infrared Systems Thermovision 900 Series, User's Manual.

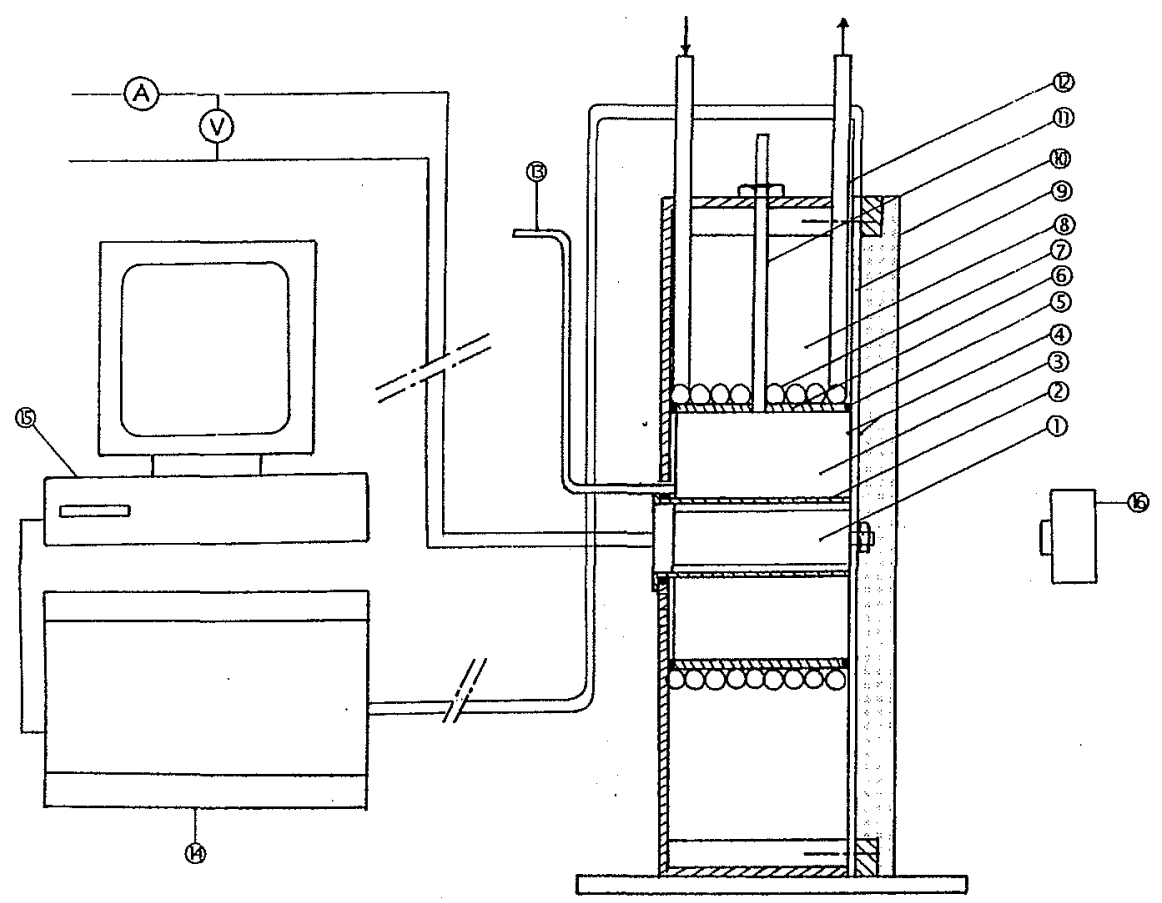

Fig. 1. Experimental set-up used for measurements: 1 -electrical heater, 2 -inner cylinder, 3 -PCM gap, 4 -reference thermocouples, 5-O-ring, 6-outer cylinder, 7 -water coil, 8 - insulation material gap, 9 -acrylic window, 10 -insulation material on the front plate, 11 -feeding tube, 12 -connection tube to the thermostat, 13 -overflow tube, $14-$ multichannel recorder, 15 - computer, 16 - IR camera. 


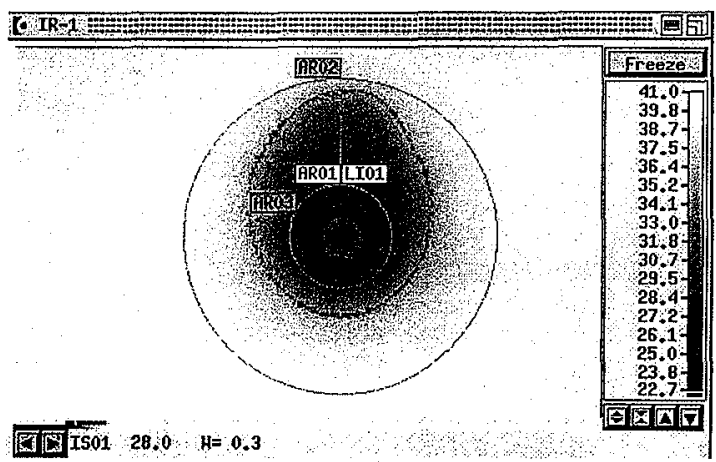

Fig. 2. An example of experimental results analyzed with use of ERIKA 3.11. software.

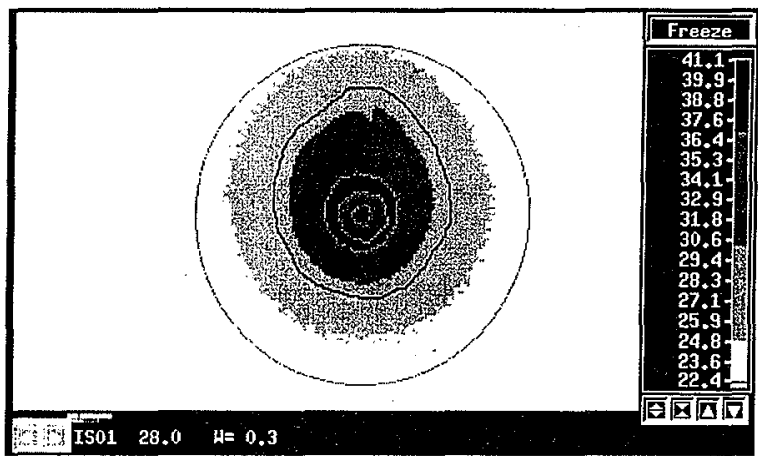

time $50 \mathrm{~min}$

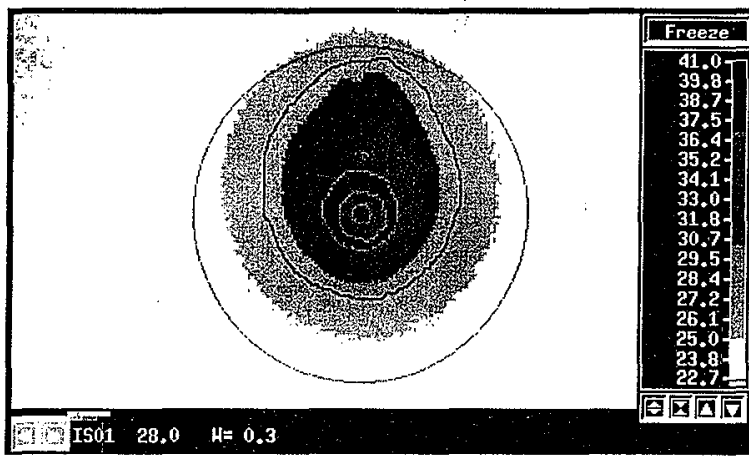

time $70 \mathrm{~min}$

Fig. 3. Time variation of the melting front shape and temperature field during melting with Ste $=4$ and $5^{\circ} \mathrm{C}$ of initial subcooling (solid line - front shape and isotherm $28^{\circ} \mathrm{C}$ ) 
http://dx.doi.org/10.21611/qirt.1996.029

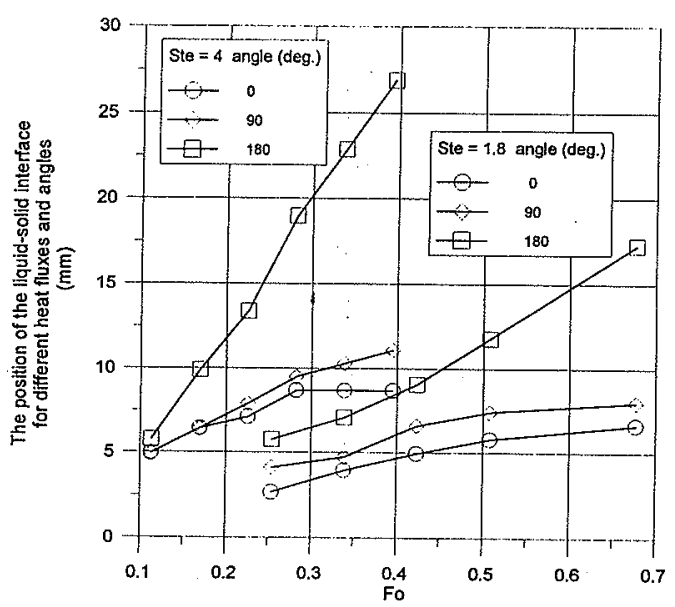

Fig. 4. The position of the solid-liquid interface as a function of Fo number for different heat fluxes and three angular positions.



Fig. 5. Time variation of the dimensionless melt volume $\left(V_{m} N_{a}\right)$ for different Ste numbers 